\title{
História imperial, ciência e poder: a disputa de fronteira anglo-brasileira
}

Imperial History, Science and Power: The Anglo-Brazilian Border Dispute

\author{
Carlo Maurizio Romani *,
}

\section{Resumo}

$\mathrm{O}$ artigo trata da ciência como veículo produtor de um discurso de verdade sobre a disputa diplomática por limites geográficos entre diferentes nações no século XIX. A mudança do estatuto que a ciência adquiriu entre os séculos XVIII e XIX como instrumento para solução de conflitos é trabalhada especificamente na análise do caso da disputa anglo-brasileira pelo Pirara, terras fronteiriças entre Roraima e Guiana Inglesa, lugar de encontro da bacia do rio Essequibo com a do Amazonas. A ciência inglesa manifestou-se na disputa com o Brasil produzindo um mapeamento cartográfico muito bem elaborado, construtor de um discurso do verdadeiro sobre o território. A representação gráfica, mais do que a ocupação humana, teve função legitimadora da posse territorial na disputa judicial sobre o Pirara. O discurso da autoridade científica baseou-se na obra cartográfica produzida por Robert Schomburgk (1840; 1841; 1843),

\section{Abstract}

This article deals with science as a vehicle able for producing a truth speech on the diplomatic dispute over geographical boundaries between different nations in the nineteenth century. The change of status that science acquired since the eighteenth up to the nineteenth century as a tool for conflict resolution is specifically analyzed in the case of the Anglo-Brazilian dispute of Pirara, the borderland between Roraima and British Guiana, a meeting point between the Essequibo River basin and the Amazon Basin. In the frontier dispute with Brazil, English science produced a very well-drawn cartographic mapping, constructor of a discourse of the true about the territory. The graphic representation, more than the human occupation, had legitimizing function of the territorial possession in the judicial dispute of Pirara. The discourse of the scientific authority was established from the cartographic work produced by Robert Schomburgk $(1840 ; 1841 ; 1843)$, whose

\footnotetext{
* Universidade Federal do Estado do Rio de Janeiro (UniRio), Rio de Janeiro, RJ, Brasil. carlo.romani@ unirio.br <https://orcid.org/0000-0002-9902-0401>
} 
cuja passagem pela região pode ser definida como o ponto de inflexão nessa disputa (Figura 1).

Palavras-chave: história imperial; ciência; fronteiras; Pirara. passage through the region could be defined as the point of inflection in this dispute.

Keywords: imperial History; science; borderlands; Pirara.

O estudo das viagens científicas em direção à região de passagem entre o rio Branco e o Essequibo nos leva a problematizar o encontro de duas lógicas diferentes no exercício do poder soberano que se confrontaram na definição dos limites entre o Brasil e a Guiana Inglesa durante o século XIX. Embora diferentes no modo de operar, ambas as soberanias (a inglesa e a brasileira) foram movidas pela construção de uma história imperial. A expansão imperialista britânica fomentou uma produção historiográfica pouco preocupada com as realidades locais encontradas em suas diferentes colônias e com a compreensão que essas populações nativas tinham sobre o espaço habitado, suas rotas, trocas e marcos naturais, elementos sem os quais a própria colonização e a escrita dessa história não teria sido possível. No entanto, a crítica à história imperial britânica, à expansão de suas fronteiras e à forma como trabalhou a literatura, a geografia e a cartografia que permitiram essa produção histórica, vem sendo feita por diversos autores desde a década de $1970 .^{2}$

No Brasil, a abordagem do caráter imperialista da expansão luso-brasileira ainda é realizada de modo tímido, ou distante dos centros hegemônicos da produção historiográfica nacional. ${ }^{3}$ A expansão territorial na América portuguesa não pôde prescindir de três estratégias complementares: uma incursão militar aos territórios fronteiriços; acompanhando essa empresa, o levantamento dos recursos e das potencialidades do território; e a produção de uma documentação literária, se possível cartográfica, apresentada posteriormente pela diplomacia. Essas viagens de exploração, depois missões científicas, às áreas mais remotas da Amazônia, tornaram-se escassas ao final da soberania portuguesa e durante o Primeiro Reinado. De fato, essa fase do Império se configura como a continuidade dos interesses luso-brasileiros, portanto, uma fase não expansionista, mas de luta pela manutenção da unidade territorial.

Se por um lado, as missões de exploração inglesas dirigidas àquela mesma área de fronteira também foram movidas por uma prática de controle e expansão dos domínios territoriais, por outro estiveram muito mais preocupadas em legitimá-la com a exploração científica do lugar, fortemente embasada em um instrumental técnico, do que em apenas fincar a bandeira num fortim para 
marcar fisicamente a presença. Os exploradores, além de perscrutarem ao limite o conhecimento sobre o território, municiaram o crescente capitalismo inglês com um inventário precioso dos recursos naturais existentes, ao mesmo tempo que vislumbravam a viabilidade comercial desses recursos. Dirigidas por esse pressuposto técnico-científico, a maioria das missões inglesas foi liderada por naturalistas e não por engenheiros, como o foram aquelas luso-brasileiras.

É verdade que durante a primeira metade do século XIX a entrada desses naturalistas também ocorreu a serviço do Reino e depois do Império, continuando uma prática anterior de controle territorial, qualificando e classificando a riqueza natural: Von Martius, Langsdorff e Saint-Hilaire foram alguns nomes notórios. Entretanto, suas viagens exploratórias não alcançaram as terras limítrofes, ainda sujeitas a disputas com as nações vizinhas. A relação entre ciência e poder mudou de figura durante o Segundo Reinado com a circulação internacional do conhecimento (Domingues, 2013). As expedições dentro do país adquiriram um claro componente científico, alcançando e atravessando até mesmo as áreas litigiosas de fronteira.

Neste artigo trataremos das terras fronteiriças dos rios Tacutu e Maú, lugar de encontro da bacia do rio Essequibo com a do Amazonas. A lógica inglesa esteve muito mais preocupada com a expansão comercial, base do domínio imperialista, do que com o mero domínio sobre o território muitas vezes sem nenhum retorno lucrativo, base da lógica territorial que ainda impregnou as missões de exploração brasileiras durante a maior parte do século XIX. ${ }^{4}$ Somente nas últimas décadas do Império e com a chegada da República, resultado do trabalho de diplomatas como Ponte Ribeiro, Joaquim Caetano da Silva, Barão do Rio Branco e Joaquim Nabuco, houve uma internalização de parâmetros técnicos na concepção da exploração física das áreas fronteiriças nacionais, e ainda assim continuou mais movida pela lógica de domínio territorial do que pela efetiva exploração comercial do território.

A ciência inglesa manifestou-se na disputa limítrofe com o Brasil produzindo um mapeamento cartográfico muito bem elaborado, construtor de um discurso do verdadeiro sobre o território. Foi essa representação gráfica, mais do que a ocupação humana, que passou a ter função legitimadora da posse territorial (Harley, 1988). Os referenciais baseados na história da geografia (ou de suas representações, melhor dizendo) foram usados pela Coroa britânica para fazer prevalecer sua visão na disputa judicial sobre o Pirara. Nessa questão limítrofe, o discurso de autoridade científica estabeleceu-se com base na obra cartográfica produzida por Robert Schomburgk (1840; 1841; 1843), cuja passagem pela região pode ser definida como o ponto de inflexão na disputa. 


\section{O Pirara}

A presença inglesa na Guiana remonta a 1803, mas a posse somente se efetivou no ano de 1814, com o tratado celebrado com a Holanda pelo qual os britânicos a compensaram da perda do Demerara. De forma bem sucinta, a questão do Pirara foi um conflito fronteiriço entre o Brasil e a Inglaterra. $\mathrm{Na}$ perspectiva do governo brasileiro, a região em litígio lhe pertenceria, já que a presença europeia mais próxima seria aquela estabelecida no Forte de São Joaquim, construído em 1777 pelos portugueses no encontro do Uraricoera com o Tacutu, rios formadores do Branco. O início do litígio começa em 1838 com a chegada da missão protestante inglesa liderada pelo reverendo Thomas Youd, vinda de Georgetown, para realizar trabalho assistencial junto aos índios Makuxi estabelecidos em Pirara, vilarejo localizado em uma área de savana próxima a um dos afluentes do Essequibo. A interferência de uma potência estrangeira, mesmo que com o pretexto de ser uma missão religiosa em defesa de índios em risco de escravização, provocou reação da autoridade imperial brasileira durante o período regencial, preocupada em manter unido o território nacional. A alegação de que as terras do Pirara seriam brasileiras com base em uma histórica ocupação humana foi contestada pela missão religiosa e em seguida pelo governo britânico, que reconheceram a precedente presença indígena como prova de ausência da soberania portuguesa. A presença Makuxi na área entre os rios Branco, Tacutu, Maú e Rupununi vem de longa data e aparece descrita desde os primeiros relatos de europeus sobre a região, no início do século XVIII (Santilli, 2000).

Com o Império envolvido em uma sucessão de rebeliões em diversas províncias, a tensão diante da ocupação inglesa acentuou-se quando autoridades militares saídas do forte de São Joaquim em incursão a Pirara entraram em contato com a missão de Youd e o acusaram formalmente de estar em terras brasileiras. O relatório do presidente da província do Grão-Pará, Bernardo de Souza Franco, ao Ministério das Relações Exteriores no Rio de Janeiro, alertava para a presença inglesa no Pirara, mas descartava uma possível invasão militar do Brasil. ${ }^{5} \mathrm{O}$ incômodo maior talvez tenha sido causado com a chegada de Robert Schomburgk, que pousou no Forte de São Joaquim em 1838, antes de iniciar sua jornada cartográfica em busca do divisor de águas entre o Orinoco e o Essequibo, na vertente norte do Monte Roraima ${ }^{6}$ (Rivière, 1995). A presença de uma missão científica amplamente capacitada do ponto de vista técnico acendeu o sinal de alerta nas autoridades militares do Alto Amazonas que ocuparam a vila de Pirara em 1841 e expulsaram de lá o missionário. A 
movimentação militar britânica foi rápida e levou a uma retirada das forças brasileiras, antes que ocorresse um conflito armado. Com a elevação do grau de tensão na área fronteiriça, a diplomacia de ambos os países mobilizou-se. ${ }^{7}$ Entre setembro de 1842 e o fim do litígio a região esteve neutralizada, estratégia usada em diferentes disputas internacionais para evitar o confronto. A indefinição diplomática fez a questão ser mantida até o ano de 1904, quando a demarcação final dos limites foi decidida em Milão mediante uma arbitragem internacional conduzida pelo rei Vittorio Emanuele III. Após o estudo das memórias entregues pelos relatores de cada país em defesa de suas causas, o laudo arbitral deu favorecimento ao governo inglês, que recebeu praticamente dois terços da área litigiosa. ${ }^{8}$

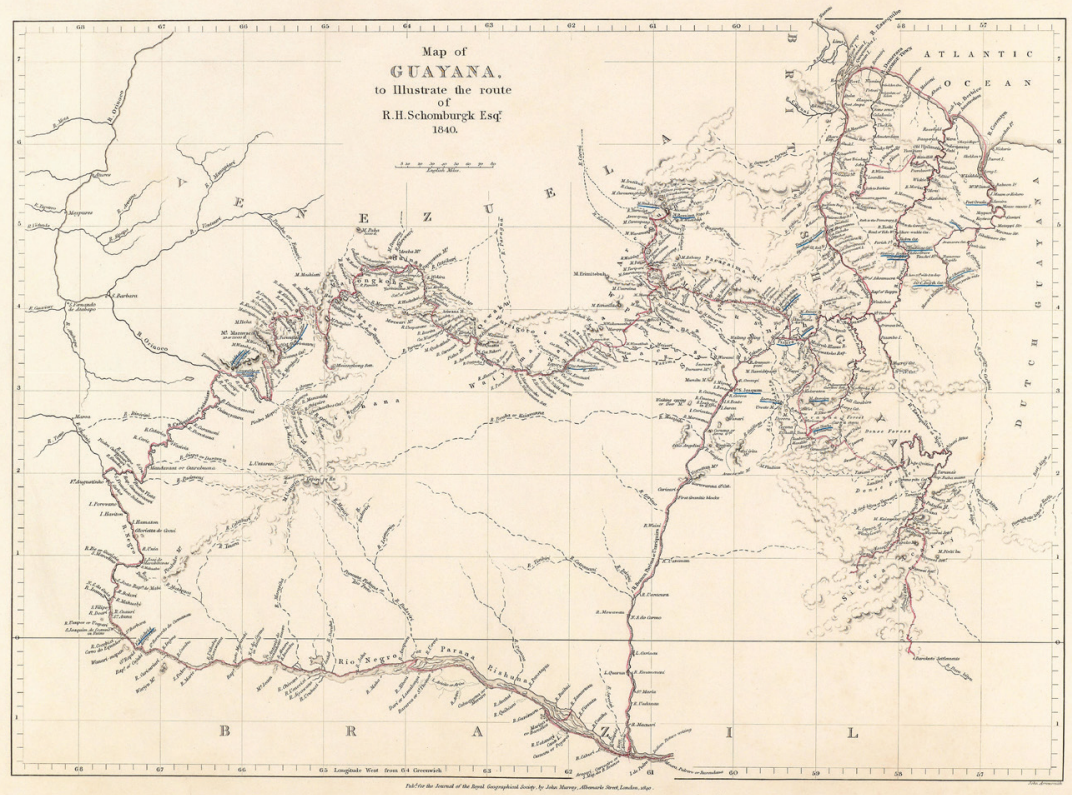

Figura 1 - Mapa da Guiana, por R. H. Schomburgk, 1840.

Fonte: Schomburgk, 1840.

Foram três as principais causas inglesas propostas na questão. Em primeiro lugar teria havido uma significativa presença holandesa na região das nascentes do Essequibo desde meados do século XVIII, o que se poderia comprovar pelos utensílios de ferro encontrados junto a diferentes povos indígenas e relatados por missões portuguesas da época para ratificar a 
importância da vigilância militar no vale do rio Branco. Em resposta, a defesa brasileira disse que os restos materiais encontrados não significariam, necessariamente, a existência de um assentamento ou uma presença efetiva de holandeses na região, mas somente a prática de um comércio local entre os holandeses e os povos indígenas. De fato, durante o século XVIII a vigilância do rio Negro foi uma preocupação contínua das tropas portuguesas para impedir o comércio de holandeses e espanhóis com as populações indígenas (Farage, 1991; Souza Jr., 2010). Seguindo a primeira lógica, a sucessão à antiga colônia holandesa, oficializada em tratado desde 1814, legitimaria a soberania inglesa sobre a região. Por fim, uma questão que custou muito caro ao governo brasileiro: a reclamada causa humanitária de Youd na defesa das populações indígenas. Ao mostrarem a região de Pirara não como espaço ocupado economicamente por assentamentos humanos brasileiros, mas sim como espaço cuja serventia apresentava-se basicamente para o apresamento de índios, a memória britânica enfraqueceu significativamente a defesa brasileira.

\section{A exploração do VAle do Rio Branco no século XVIII}

É quase um consenso na bibliografia encontrada, salvo raras exceções, ${ }^{9}$ de que o médico e comerciante prussiano Nicholas Horstman, comissionado a serviço do governo da colônia holandesa da Guiana, foi o primeiro explorador a conseguir passar da bacia do Essequibo para a do Amazonas, através de Pirara, descendo o rio Branco - ou, pelo menos, foi o primeiro explorador a produzir documentação sobre isso. Partindo em 1739 de Demerara, Horstman conseguiu essa primazia subindo o Rupununi, afluente do Essequibo, atravessando a savana na altura de Yupukarri em direção a Pirara, uma importante área de junção de rotas indígenas, conhecida pelos comerciantes holandeses, segundo Rivière (1995, p. 2), desde 1660. Da vila de Pirara, às margens do lago Amucu, o médico alemão seguiu até o rio Maú e o desceu até encontrar o Tacutu; daí, rio abaixo alcançou o Branco. Os croquis por ele desenhados, capturados pelo governo colonial no Grão-Pará, foram primordiais para a obtenção de um maior conhecimento sobre a intersecção entre a bacia amazônica e a do Essequibo e para a construção de uma história geográfica da Guiana e de Roraima. ${ }^{10}$

Mesmo sem ter consciência do feito - acreditava ter estado em outro lago que não o Parima -, Horstman alcançou aquele que seria o decantado Eldorado de Walter Ralegh. Em dezembro de 1743, ao chegar a Belém do Pará, encontrou-se com La Condamine, interessado na comunicação entre o rio Negro e 
o Orinoco, que se dirigia a Caiena após longa expedição pelo Amazonas (Minguet, 1992, p. 13-16). Horstman confiou-lhe seus apontamentos que foram usados por Jean-Baptiste d'Anville para a elaboração de sua Carte de l'Amerique Meridionàle ${ }^{11}$ (Burnett, 2000, p. 31; Furtado, 2013, p. 715-717). No começo do século XIX, as anotações e os desenhos de Horstman guardados em Paris chegaram ao conhecimento de Humboldt, que procedia a um levantamento geral da cartografia das Guianas antes de sua histórica viagem à Venezuela. Ao estudar as diversas cartas deteve-se na rota percorrida por Horstman e em sua descrição das terras alagadas próximas a Pirara e ao lago Amucu, e percebeu que de fato ele havia chegado ao lendário lago de Parima. Humboldt não via contradição entre as narrativas orais dos povos ameríndios para a existência de um grande mar interior, o Parima ou Manoa, e o encontro somente da pequena área alagada em Amucu. Na época das chuvas, as cheias dos rios formadores, tanto do Essequibo quanto do Branco, e mesmo do Orinoco, em uma bacia hidrográfica de vegetação de savana plana, podem causar a ocorrência de uma vasta área inundada através de seus canais comunicantes (Burnett, 2000, p. 25-33).

A vitória portuguesa sobre os índios Manao no rio Negro, após intensas guerras durante a década de 1720, facilitou a continuidade das missões ao rio Branco para ampliar o reconhecimento do lugar, além de incrementar os aldeamentos e a captura para escravização em Belém de índios de diferentes nações de filiação linguística Carib e Aruak (Farage, 1991, p. 65-69; Oliveira, 2003, p. 75-89). Destacam-se as viagens do comerciante de escravos Lourenço Belfort que, subindo o Uraricoera por volta de 1740, teria realizado o apresamento de cerca de mil indígenas de uma só vez em uma incursão junto a Francisco Ferreira. A passagem, repetida em diversos relatos colhidos junto aos indígenas, causou viva impressão no ouvidor Francisco Xavier Ribeiro Sampaio. Posteriormente, em 1748, foi a vez de José Miguel Ayres unir-se a Belfort na última entrada oficial para o apresamento de indígenas. ${ }^{12}$ Mesmo a par da passagem fluvial, nenhuma das duas expedições conseguiu alcançar a região do Pirara. Do ponto de vista estratégico, a presença militar portuguesa serviria também para desestimular a circulação de comerciantes ou exploradores holandeses, a exemplo de Horstman. O principal objetivo dessas expedições era o de confrontar a possível presença holandesa e espanhola nos rios Tacutu e Uraricoera, respectivamente, para garantir a soberania portuguesa sobre o território. Apesar de alguns relatos advertirem para uma possível ocupação holandesa no alto Essequibo desde a metade do século XVIII, ela não parece ter sido provável. ${ }^{13}$ 
Nos 20 anos que se seguiram à assinatura do Tratado de Madri (1750), que buscou definir as áreas sob domínio espanhol e português com base no uti possidetis e nas "fronteiras naturais", percebe-se a preocupação da parte dos portugueses em garantir seus domínios sobre o alto rio Negro em bases cartográficas mais precisas. Remonta a essa época a constituição das Comissões Demarcadoras de Limites, missões bilaterais de espanhóis e portugueses, cada lado procedendo à prospecção do território que julgava pertencer-lhe (Bastos, 2017, p. 149-293). Do lado espanhol, a contenção do avanço dos "caçadores de escravos", como os lusitanos eram vistos pelos estrangeiros, implicava a delimitação fronteiriça entre a Guiana venezuelana e o Grão-Pará. Em 4 de outubro de 1759, descendo o canal do Cassiquiare, o sargento Francisco Fernandez de Bobadilla chega a Mariuá (Barcelos), já no rio Negro, onde encontra o tenente-coronel Souza Filgueiras, remanescente da comissão portuguesa (Lucena Giraldo, 1993, p. 207). Cinco anos antes, já houvera o reconhecimento oficial da comunicação aquática entre o Orinoco e o Negro pelas comissões de limites dos dois países, ratificando um fato conhecido desde 1744. Trata-se do relato do jesuíta estabelecido numa missão junto ao Orinoco, Manuel Román, que ao perseguir portugueses apresadores de índios tornou-se o primeiro a documentar aquela travessia. O relato chegou até La Condamine, em Paris, enviado pelo então chefe do Colégio Jesuíta do Pará, padre João Ferreira, que reconhecia a hipótese de as águas do Orinoco formarem por declive o Cassiquiare (Alès; Pouyllau, 1992, p. 285, 294 n. 44).

Se a prospecção demarcatória do alto rio Negro ganhara importância para a comunicação das duas grandes bacias hidrográficas, o acesso ao alto rio Branco sempre se apresentou de forma mais difícil e nem sempre esteve ao alcance das comissões demarcadoras. Em 1766 foi organizada uma expedição portuguesa de reconhecimento acompanhada de forte destacamento militar liderado pelo alferes José Agostinho Diniz, que logrou êxito em subir até o Maú, precedendo a entrada posterior da comissão demarcadora sem, contudo, mapeá-lo. ${ }^{14}$ Durante os anos de 1774 e 1775 o ouvidor Francisco Xavier Sampaio realizou diversas viagens pelo Amazonas e escreveu um longo relato do histórico da ocupação do vale do rio Branco. Mostra um bom conhecimento sobre os rios e populações locais. O ouvidor não deixa de citar a "decantada fábula do lago dourado", que, com ironia, chama de "pequeno rio Parimi”. Em seu relato, deixa evidente que os espanhóis também estiveram em busca do lendário lugar. Para evitar o avanço dos espanhóis, o ouvidor aconselha ao governo do Grão-Pará que construa uma fortificação e ocupe as terras com grandes fazendas de gado (Sampaio, 1825, p. 99), atividade pecuária que será 
introduzida por Manuel da Gama Lobo d'Almada ao final da década seguinte. ${ }^{15}$ Com a assinatura do Tratado de Santo Ildefonso em 1777, mais desfavorável aos portugueses, a construção do forte de São Joaquim na zona de confluência dos afluentes formadores do rio Branco insere-se em uma estratégia defensiva da Coroa portuguesa, buscando constituir aldeamentos indígenas no vale (Vieira; Gomes Filho, 2013, p. 110-117). Mesmo sendo reconhecida nos mapeamentos realizados a presença de uma enorme diversidade de nações indígenas, especialmente a Makuxi, a região ao norte do rio Branco continuava sendo tratada como mais um vazio demográfico a ser ocupado. Apenas terras sob o risco de incursão de gentio bravio, o que autorizaria e legitimaria seu apresamento, mesmo que oficialmente proibido pela Coroa.

É importante circunscrever que houve uma mudança de olhar em relação ao vale do rio Branco após o fracasso do Tratado de Madri. Para os portugueses, o inimigo mais próximo deixara de ser o holandês e passara a ser a presença de militares espanhóis, que vindos pelo Orinoco contornavam o platô do Roraima, descendo ora o rio Uraricoera, ora o Maú, ambos já na bacia amazônica. Podemos, assim, falar em dois ciclos de explorações portuguesas à região destacadas do caráter diplomático, que sugeriria a montagem conjunta de comissões demarcadoras: o primeiro na década de 1740 em resposta ao "perigo" holandês, e o segundo na década de 1770 diante do "perigo" espanhol. Até fins do século XVIII um dos trabalhos dos exploradores será o de tentar encontrar as pretendidas fronteiras naturais entre o que seria o território sob o controle português e aquele sob o espanhol. Desde os escritos deixados pelo ouvidor verifica-se a importância da produção de uma memória sobre o protagonismo português na ocupação territorial.

Segundo Antônio Carlos Robert Moraes, o Brasil foi concebido como um espaço a ser conquistado, o que guiou e legitimou as ações de interiorização promovidas pelo Estado. Dessa forma, a conquista do território deu-se pelo avanço dos "fundos territoriais", áreas distantes a serem alcançadas para demarcar a presença portuguesa e garantir sua soberania na região, áreas aguardando uma futura ocupação, geralmente com a construção de um posto militar, eventualmente com a exploração agrícola do entorno. Esse tipo de ocupação precária sustentou a narrativa da história diplomática brasileira, especialmente na questão das fronteiras nacionais, percebidas como lugares da presença da civilização na selva, um dos atributos da construção da identidade nacional (Moraes, 2002, p. 109-111). Mesmo nas áreas mais distantes da Amazônia, onde a presença luso-brasileira era mínima, houve sempre um esforço argumentativo para legitimar a posse da fronteira. Nesse sentido, não há 
contradição no discurso oficial ao apresentar o elemento nacional como desbravador da natureza e combatente de índios hostis.

Continuando as incursões ao rio Branco, junto à passagem do ouvidor Francisco Xavier de Sampaio no ano de 1775 estiveram o capitão Phillipe Sturm e Gaspar de Gronsfeld, engenheiros alemães enviados para trabalhos demarcatórios da Primeira Comissão no rio Negro e afluentes, e que tiveram também a incumbência de coordenar a construção do Forte de São Joaquim. Sob o comando de Sturm, foi produzido um primeiro conjunto cartográfico dos rios Branco, Catrimani e Uraricoera, contornando toda a base do maciço de Roraima. Além dos trabalhos técnicos, Sturm também é lembrado por atacar e rechaçar posições espanholas estabelecidas no rio Uraricoera, a última delas em Santa Rosa, e impedir o avanço de militares pelo Tacutu, indicando a promiscuidade entre a empresa científica e aquela de defesa e conquista.

Entre dezembro de 1780 e maio de 1781 será a vez de o capitão Ricardo Franco de Almeida Serra, cartógrafo, e o geômetra e astrônomo Antônio Pires da Silva Pontes empreenderem viagem à área entre os rios Tacutu e Rupununi, deixando pela primeira vez uma documentação escrita para a Coroa portuguesa. ${ }^{16}$ Saindo de São Joaquim, essa empresa deu continuidade aos trabalhos anteriores de Sturm, avançando para o nordeste em direção à Guiana. Realizada sob o comando de Pereira Caldas no âmbito da Segunda Comissão, já após ter sido assinado o Tratado de Santo Ildefonso, pode ser considerada a primeira expedição científica portuguesa a chegar próximo à região do Pirara. Portugal passa a imaginar suas fronteiras com a Espanha pelo corte dos rios Rupununi e Anauau. Embora a passagem de Almeida Serra tenha sido cercada de controvérsias em Lisboa em virtude da qualidade do trabalho efetuado, em comparação às anteriores podemos identificar nela um claro objetivo científico, além daquele militar também destacado em seu relatório ao afirmar a necessidade do estabelecimento de um posto no Rupununi, preventivo contra as invasões espanholas.

O fracasso dessa expedição, na ótica da Corte portuguesa, seria reparado com o envio ao vale do rio Branco de Manoel da Gama Lobo d'Almada entre 1786 e 1787. Explorador português de maior tino comercial da época, d'Almada teria a missão de "retomar os trabalhos de indagação não completados" anteriormente (Reis, 2006, p. 17). Acompanhado do matemático José Simões de Carvalho, quem de fato fez as medições topográficas e desenhou os mapas produzidos na viagem, a expedição de Lobo d'Almada subiu o rio Tacutu até o Sarauru e posteriormente atravessou os campos para o rio Rupununi. Principal ideólogo da colonização dos campos altos do rio Branco com 
fazendas de gado, d'Almada produziu extenso relato sobre a fauna e a flora da região, no qual busca demonstrar as vantagens econômicas que sua exploração traria ao governo português (D’Almada, 1861). Assim como o ouvidor Ribeiro Sampaio, desacreditava da existência de um Eldorado em terras da Guiana, mas não excluía a possibilidade da presença de diamantes ou outras pedras preciosas, embora não tivesse competência para efetuar a prospecção mineral da região. Pensou, contudo, na possibilidade da produção comercial de algodão após notar a existência da cultura em povoados indígenas (Rio Branco, 2012, p. 51).

Quase que contemporaneamente à passagem de Lobo d'Almada, chegou ao rio Negro uma missão científica propriamente dita, desprovida do caráter militar que financiou as anteriores. O naturalista Alexandre Rodrigues Ferreira, nascido em Salvador da Bahia e crescido em Coimbra, onde estudou História Natural, foi um dos nomes mais reputados da ciência colonial portuguesa, e os trabalhos por ele publicados após sua viagem pela Amazônia superam largamente os relatos anteriores deixados pelos viajantes a serviço da Coroa. Em sua ida ao rio Negro, Rodrigues Ferreira (1972) passou pelo vale do rio Branco no ano de 1787 e subiu o Tucutu em direção ao norte até o rio Maú, e depois retornou pelo mesmo rio em direção ao sul até a serra do Urubu, não tendo atravessado os campos em direção ao Rupununi. A formação científica de Rodrigues Ferreira ocorreu durante o período pombalino, regime que teve uma visão bastante utilitarista da ciência, muito próxima à da revolução científica em curso na Inglaterra. De certo modo, a visão de Ferreira completa a percepção comercial tida por d'Almada: a exploração territorial não deveria reter-se apenas no reconhecimento do lugar, mas fomentar as atividades agrícolas e comerciais da economia colonial. A atividade do cientista "naturalista transformava o saber em prática quando este revertesse em benefício para o Estado”, ligação ainda marcante na nascente ciência portuguesa (Raminelli, 1998, p. 177).

A viagem 'filosófica' de Ferreira, para distingui-la das empresas basicamente preocupadas somente com a conquista territorial, pode ser considerada como a primeira e única expedição científica de fato empreendida por portugueses e brasileiros até o rio Negro. A concepção utilitarista da ciência declinará com o fim do período pombalino, e o Império português reafirmará sua vocação para grande império territorial dos trópicos, seguindo o caminho oposto ao realizado pelos britânicos. Em sua obra observamos pela primeira vez nos relatórios portugueses estudos descritivos bastante extensivos da fauna e da flora, além de uma preocupação econômica, com as atividades agrícolas possíveis de serem desenvolvidas a fim de 'civilizar' os índios nativos. Nesse 
ponto, Ferreira pode ser lido como um dos grandes narradores da história imperial luso-brasileira, uma construção voltada para a conquista do território que ignora as populações indígenas, percebendo-as apenas como selvagens a serem utilizados, domesticados ou exterminados, evidente no tratamento dado aos tapuias, mamíferos classificados como primatas pelo seu grau de organização moral e política; ou na utilização prática do saber indígena em suas descrições sobre o alto rio Branco (Ferreira, 1972, p. 93); assim como no pouco caso dado aos aldeamentos indígenas já existentes, em contraponto ao significativo destaque que receberam grupos hostis, agressivos ao contato português, como os Mura.

\section{O SÉCUlo XIX E A CHEGADA DA CIÊNCIA INGLESA}

A partir do início do século XIX o interesse luso-brasileiro pelo vale do rio Branco diminuiu, refletindo-se no aporte aos militares alocados em São Joaquim. A ocupação com a pecuária manteve-se "uma atividade marginal, ainda mais devido às dificuldades de transporte, permanecendo por longo tempo, até o final do século XIX, como uma atividade de subsistência e subsidiária do extrativismo vegetal" (Vieira; Gomes Filho, 2013, p. 115). Das três fazendas constituídas inicialmente, as duas pertencentes a particulares foram confiscadas pelo Estado após a morte dos fazendeiros, e, quando da passagem de Schomburgk pela região, em 1838, ele relatou a presença nos campos do Tacutu de uma grande quantidade de rezes selvagens sem condução (Rivière, 1995, p. 4). Diversas causas podem ter levado ao declínio: o perigo espanhol já não amedrontava mais; os holandeses haviam passado a colônia às mãos dos britânicos; ou porque o foco das atenções desviou-se da Amazônia para a região platina. As sucessivas crises políticas decorrentes do processo de independência impediram a manutenção de um esforço imperial em continuidade à prática portuguesa de povoamento da região. A exceção coube à extensa expedição financiada pelo governo austríaco, da qual fez parte Johann Naterrer. O naturalista e zoólogo austríaco visitou por 10 meses o vale do rio Branco entre 1832 e 1833, antes de seu regresso a Viena, deixando importante trabalho, principalmente sobre a avifauna da região, como indicam Barbosa e Ferreira (1997).

Serão os ingleses, novos 'proprietários' do antigo Demerara holandês, a fazer valer seus objetivos na Guiana. Desde 1803 e até a chegada da futura missão de Schomburgk, diversas expedições científicas foram financiadas pela British Guiana Boundary Comission, para levantar e definir o limite leste com a possessão holandesa (Burnett, 2000). Alguns desses viajantes, entretanto, 
alcançaram as futuras áreas de litígio, ao sul com o Brasil e a oeste com ex-colônia espanhola. A primeira incursão inglesa em direção ao Brasil remonta a 1810, quando o médico John Hancock, radicado em Georgetown, foi incumbido pelo governo colonial de estimar a quantidade de população ameríndia existente no interior da Guiana e avaliar o grau de ameaça que ela representaria. A missão de Hancock praticamente repetiu o percurso que consagrara anteriormente Horstman: chega ao forte São Joaquim e retorna. Logo em seguida, em quatro viagens empreendidas entre 1812 e 1824, o explorador e botânico Charles Waterton (1973) subirá o curso do Rupununi e o atravessará pelas savanas alagadas até alcançar São Joaquim em 1817, deixando redigida para a Coroa britânica uma envolvente narrativa da fauna, flora e das populações dessa nova hinterland colonial inglesa, além das primeiras medições e impressões sobre a fronteira com o Brasil. Em 1820, em outra expedição, o tenente naval Gullifer e o mercador Smith repetiram a mesma rota e a continuaram até Manaus, onde Smith faleceu (Rivière, 2006, p. 19).

Após a avaliação da demografia indígena regional, o governo colonial na Guiana incentivará o estabelecimento de missões protestantes junto às aldeias do vale do Essequibo e afluentes meridionais, em terras Makuxi, Arecuna e Wapixana. A já relatada chegada de Thomas Youd ao Pirara fez parte dessa política missionária, cujas primeiras incursões ao interior da Guiana remontam a 1829, seguidas do estabelecimento da missão catequizadora de John Armstrong em Bartica Point, ainda em território Carib, no ano de 1831. Dois anos depois, Armstrong subiu o Rupununi e travou contato com os Makuxi em Pirara, um aldeamento sazonal na estação seca. Essa breve cronologia da ocupação religiosa inglesa interessa ao nosso estudo até maio de 1838, quando Youd fixou-se em Pirara com o consentimento dos Makuxi (Rivière, 1995, p. 10). A política britânica de ocupação interior da colônia seguia um roteiro de levantamento científico prévio do território e da população, respaldado por um destacamento militar na retaguarda e seguido por entradas missionárias. Diferentemente da histórica ocupação portuguesa, na qual a missão religiosa estabelecia-se junto à praça forte, na colonização britânica o discurso evangelizador dispensava a construção de postos militares, o que não significava que descartassem o amparo militar. Quando precisaram de apoio, os ingleses recorreram ao Forte São Joaquim, como no primeiro socorro oferecido pelo capitão José Valente Cordeiro em 1835 aos membros da expedição de Schomburgk acometidos de febre (Rivière, 1995, p. 17-18).

Nesse mesmo ano, a Royal Geographical Society financiou uma missão de reconhecimento da fauna e flora do vale e afluentes do Essequibo e do 
Rupununi, e de demarcação das rotas de acesso ao Monte Roraima. O geógrafo alemão Robert Schomburgk encontrava-se em serviço nas ilhas Virgens britânicas quando foi convidado para dar continuidade à tradição de pesquisa de Humboldt na América do Sul (Burnett, 2000, p. 92-99). Nessa primeira viagem, Schomburgk conheceu a região de Pirara e manteve um contato inicial com os militares brasileiros em São Joaquim. O envolvimento demonstrado pelo jovem alemão garantiu-lhe outras duas missões. A terceira, entre os anos de 1838 e 1839, o levou de volta a Pirara para completar o levantamento topográfico e demarcatório do percurso circular de subida do rio Negro, do Cassiquiare e do Orinoco até o encontro dos tributários do Essequibo nas encostas do Monte Roraima (Rivière, 2006). Essa foi sua última viagem a Pirara com financiamento da Royal Society. Depois dela, Schomburgk ainda retornaria à Guiana, mas a serviço do governo inglês.

A fundação da Royal Society em 1662 originou na Grã-Bretanha diversas sociedades especializadas no estudo de diferentes áreas da ciência moderna. No discurso, mantinha como um dos princípios fundadores o comprometimento da não participação de seus membros em disputas de caráter político ou religioso. Rompendo a tradição - e talvez esse tenha sido o motivo de sua saída da Royal Society -, em agosto de 1838 Schomburgk presenciou em São Joaquim a passagem de uma tropa de resgate descendo índios Wapixana para serem escravizados sob o olhar complacente de oficiais brasileiros. A partir desse momento, segundo a tese de Rivière (1995), Schomburgk aderiu completamente ao projeto de Youd, abraçando a causa 'humanitária' em defesa das populações indígenas. Na colônia inglesa da Guiana a escravidão já fora abolida desde 1833 com participação ativa dos missionários após a cruel repressão à rebelião escrava do Demerara (Costa, 1998). O discurso de defesa humanitária das populações estará presente até o fim da questão do Pirara, quando da arbitragem internacional. A denúncia da escravização indígena em meados do século XIX, se não tinha ainda alcançado grande repercussão na opinião pública inglesa por intermédio dos missionários, o terá perante a campanha desenvolvida por um homem de ciência.

Porém, o temperamento explosivo e autoritário do geógrafo alemão, relatado por Edward Goodall, artista membro da missão, no trato especialmente duro com os homens de sua equipe, destoaria do "pequeno homem" - referência à sua estatura - hábil em negociar com as autoridades brasileiras e os índios nativos sem recorrer à força armada (St John-McAlister, 2010, p. 4-7). O perfil apontado por Goodall, autoritário com diplomacia, não se assemelha de fato ao de um cientista de formação religiosa, filho de um pastor, sendo esse 
mais adequado ao Schomburgk que desponta após seu retorno a Pirara em 1841, um técnico a serviço da diplomacia britânica interessada em estender seus domínios dentro da bacia amazônica. Este segundo perfil pode sustentar a tese desenvolvida por Menck (2009) que rechaça ser a questão central da disputa fronteiriça o humanitarismo, mas algo muito mais profano, a simples conquista de um território dentro da bacia amazônica. Ambas as questões parecem pertinentes, mas devemos lembrar que em outras colônias britânicas, como durante a conquista das terras dos aborígenes na Austrália (Carter, 2010, p. 136-171), o discurso e a prática inglesa, em pleno século XIX, continuaram muito parecidos com aqueles realizados na América do Sul. ${ }^{17} \mathrm{O}$ envolvimento de Schomburgk numa questão religiosa de impacto político fará com que passe a atuar efetivamente como um agente a serviço do Estado. Segundo Rivière, como resultado desse contato o geógrafo mudou sua percepção em relação à ação a ser desenvolvida junto aos povos em Pirara, entendendo que para a manutenção de sua liberdade estes deveriam viver sob a soberania britânica, e isso significaria a definição de limites (Rivière, 2006, p. 23).

$\mathrm{O}$ arsenal de equipamentos trazido por Schomburgk para a agrimensura da área fronteiriça com o Brasil usando o método da poligonal topográfica, na época ainda apenas triangular, saltará à vista dos brasileiros quando da passagem do geógrafo. A agrimensura ainda era bastante imprecisa no início do século XIX, e mesmo quando as expedições eram acompanhadas por astrônomos e técnicos em geometria e topografia a localização das medições nas cartas de grande escala tornava-se bastante vaga: com o passar do tempo, desapareciam os marcos inscritos nos troncos de árvores frondosas. Apenas no finalzinho do século XVIII o instrumental com grandes teodolitos (Ramsden), mira telescópica e o sistema de triangulação havia-se desenvolvido a ponto de permitir a localização mais segura de marcos na definição de limites. A expedição geográfica realizada por Schomburgk entre 1835 e 1839, e depois continuada oficialmente mediante a traverse survey, circundante do perímetro limítrofe indefinido entre a Guiana, o Brasil e a Venezuela, consistiu justamente na medição trigonométrica com aparelhos de grande precisão para a época e sua marcação na caderneta de campo. Seguia-se a edificação de marcos em pontos estratégicos, geralmente margens de rios e monumentos naturais (Burnett, 2000, p. 67-118). A precisão cartográfica dos mapas desenhados posteriormente por Johan Arrowsmith com base nas informações trazidas por Schomburgk de fato o posiciona como um divisor de água na cartografia das Guianas. Nesse sentido, foi Schomburgk literalmente quem colocou a Guiana 
no mapa do Império Britânico - the red on the map - uma tarefa que estava em curso ao redor de todo o globo terrestre (Jackson, 2013, p. 13-24).

Em 1841 Schomburgk retornou à área fronteiriça, mas desta feita encarregado pela Comissão Britânica para concluir a marcação da linha fronteiriça entre Guiana, Brasil e Venezuela. ${ }^{18}$ A passagem de Schomburgk e o início da demarcação ao longo dos rios Tacutu e Maú, por ele definidos arbitrariamente como limites políticos, coerente com seu discurso de que Pirara deveria ser território britânico para proteção aos índios, desagradaram o Rio de Janeiro. O Império do Brasil internacionalizou o caso em 1842, conseguindo a neutralização do território e a instalação de uma comissão mista de limites. Isso não impediu a continuidade da atividade de Schomburgk, enquanto aguardava a vinda da missão brasileira que somente chegou ao Pirara em dezembro de 1843, quando o geógrafo alemão já se havia retirado. Nos anos seguintes, a Inglaterra voltou atrás em relação aos marcos instalados, destruindo-os e aguardando o momento de uma decisão judicial definitiva, mas não arredou mais o pé de Pirara.

A missão brasileira liderada pelo tenente-coronel Frederico Carneiro de Campos, encarregado pelo lado brasileiro da Comissão Demarcadora de Limites, chegou quase um ano após a saída da missão inglesa e permaneceu em Roraima durante o ano de 1844. Deixou por escrito um breve relato de viagem denominado Carta geográfica dos terrenos contestados entre o Império do Brasil e Guiana Inglesa. Descreve o estado de destruição deixado em Pirara e o abandono em que se encontrava o Forte São Joaquim, reduzido a uma colônia rural. Produziu também um croqui, que serviu à causa brasileira em Milão. ${ }^{19}$ Nesse desenho vê-se uma descrição muito simplificada da área do Lago Amucu, ao centro, mostrando nas laterais os rios Surumu, Maú, Tacutu, Pirara, Rupununi e afluentes. ${ }^{20}$

Os resultados da sua missão ficaram muito aquém do desejado na expectativa do Ministério das Relações Exteriores. ${ }^{21} \mathrm{O}$ pouco caso demonstrado pelo governo brasileiro na época, inclusive com a memória cartográfica produzida pelos portugueses, já se podia observar no relato deixado pelo marechal Francisco José de Souza Soares, presidente da província do Grão-Pará entre 1836 e 1839. Indignado, afirmava que a Inglaterra já tomara posse de todos os mapas no Arsenal da Marinha em Lisboa para a atualização cartográfica da região, ignorando completamente a participação de brasileiros (Andrea, 1841, p. 322-332). A legitimação da posse britânica sobre o território não foi definida pela ocupação histórica de terras ditas ignotas ou vazias, mas pela capacidade de detalhar precisamente, com o auxílio da ciência, o que julgava lhe pertencer. 
A 'imposição' de um novo modelo de produção de verdade no mundo, de um direito soberano legitimado em bases científicas, não deixa também de ser um ato de força, mesmo porque a força militar britânica de retaguarda entrou em ação em Pirara para desalojar a ocupação militar brasileira.

\section{CONSIDERAÇÕES FINAIS}

Diante da cronologia analisada neste trabalho devem ser feitas algumas ressalvas: somente podemos falar em missões científicas portuguesas a partir da viagem de Ricardo Franco, em 1781. Antes disso a prospecção científica de reconhecimento territorial estava subordinada à missão militar, principalmente se considerarmos que o principal escopo era o patrulhamento, a expulsão de estrangeiros indesejados e a submissão de populações indígenas. O início efetivo de uma construção científica ocorrerá somente com a ideia pombalina da ciência a serviço dos negócios de Estado, e ainda assim por um breve período de tempo. Já a ciência inglesa conseguiu separar-se da tutela estatal, o que lhe permitiu um crescente desenvolvimento técnico a serviço da expansão dos interesses comerciais e industriais. A participação da Coroa britânica nessas empresas ocorria de modo determinante somente ao final das atividades realizadas, geralmente para ratificar o controle sobre o território. Ao mesmo tempo, o mapeamento de praticamente todo o globo terrestre durante o século XIX não deixa de ser uma prova do uso imperialista dessa ciência.

Uma breve comparação entre os trabalhos produzidos na missão chefiada por Schomburgk e os de Carneiro de Campos evidencia a disparidade técnica entre os dois países. De fato, durante todo o período de neutralização da questão diplomática não se produziu nenhuma outra linha demarcatória que fosse diferente daquela proposta por Schomburgk. Ao final, será essa superioridade técnica e não a polêmica levantada com a causa humanitária o que garantirá à Inglaterra a vitória no arbitramento internacional. Além disso, a distância entre as duas nações não se resumia à nítida superioridade técnico-científica. Frei José dos Santos Inocentes, que teve grande participação nos momentos iniciais da disputa ao tentar montar uma missão católica em Pirara em resposta à missão de Youd, descreve a ostentação demonstrada nos jantares organizados pelos ingleses e a exibição ostensiva de armamentos usados durante a ocupação.

Se, no decorrer do século XIX, podemos afirmar que o exercício do poder no Estado moderno, justificado pela ciência, antecede a ação militar - que só ocorrerá em última instância -, modificando assim a lógica da soberania 
precedente, também é verdadeiro que, em última instância, seria ainda a guerra a definir os conflitos internacionais.

\section{REFERÊNCIAS}

ADONIAS, Isa. A Cartografia da Região Amazônica. v. II. Rio de Janeiro: Instituto Nacional de Pesquisas da Amazônia, 1963.

ALÈS, Catherine; POUYLLAU, Michel. La conquête de l'inutile: les géographies imaginaires de l'Eldorado. L'Homme, tome 32, n. 122-124, p. 271-308, 1992.

ANDREA, Francisco José de S. S. Memoria sobre o intento que tem os ingleses de Demerari de usurpar as terras ao Oeste do rio Repunuri adjacentes à face austral da Cordilheira do Rio Branco para amplificar a sua colônia. RIHGB, Rio de Janeiro, 1841.

ARRIGHI, Giovanni. O longo século XX. São Paulo: Contraponto, 1996.

BARBOSA, Reinaldo I.; FERREIRA, Efrem Jorge G. Historiografia das expedições científicas e exploratórias no vale do Rio Branco. In: BARBOSA, Reinaldo I.; FERREIRA, Efrem Jorge G.; CASTELLON, Eloy G. Homem, ambiente e ecologia no Estado de Roraima. Manaus: Inpa, 1997.

BASTOS, Carlos Augusto de Castro. No limiar dos impérios: a fronteira entre a Capitania do Rio Negro e a Província de Maynas: projetos, circulações e experiências (c.1780-c.1820). São Paulo: Hucitec, 2017.

BURNETT, Graham. Masters of All They Surveyed. Exploration, Geography, and a British Eldorado. Chicago, IL: The University of Chicago Press, 2000.

CARTER, Paul. The Road to Botany Bay: An Exploration of Landscape and History. Minneapolis, MN: The University of Minnesota Press, 2010.

COSTA, Emilia V. da. Corôas de glória, lágrimas de sangue: a rebelião dos escravos de Demerara em 1823. São Paulo: Companhia das Letras, 1998.

D’ALMADA, Manoel da G. L. Descripção Relativa ao Rio Branco, e seu Territorio. Revista Trimestral do Instituto Historico Geographico e Etnographico do Brasil, Rio de Janeiro, v. 24, 1861.

DESTRO, Marcio Antonio. Soberania no Rio Branco e a demarcação da terra indígena Raposa Serra do Sol. 2006. Dissertação (Mestrado em Relações Internacionais) Universidade de Brasília (UnB). Brasília, 2006.

DOMINGUES, Heloísa Bertol. Expedições científicas no Brasil: circulação de conhecimentos "internacionais" e de objetos científicos "locais" (séc. XIX). In: LOSADA, Janaina; PUIG-SAMPER, Miguel Ángel; DOMINGUES, Heloísa Bertol. Um álbum para o Imperador: a comissão científica do Pacífico e do Brasil. Rio de Janeiro: Mast, 2013. 
FARAGE, Nádia. As muralhas dos sertões: os povos indígenas no Rio Branco e a colonização. Rio de Janeiro: Paz e Terra, 1991.

FERREIRA, Alexandre R. Viagem Filosófica pelas Capitanias do Grão Pará, Rio Negro, Mato Grosso e Cuiabá. 2 v. Rio de Janeiro: Conselho Federal de Cultura, 1972.

FOUCAULT, Michel. Outros espaços. In: FOUCAULT, Michel. Ditos e escritos Estética: Literatura, pintura, música e cinema. v. III. Rio de Janeiro: Forense Universitária, 2009.

FOUCAULT, Michel. Sobre a geografia. In: FOUCAULT, Michel. Microfísica do poder. Rio de Janeiro: Graal, 1996.

FURTADO, Junia F. Mapping Mythical and Imaginary Places in d'Anville's Carte de l'Amérique Méridionale. Journal of Earth Science and Engineering, v. 3, p. 714-721, 2013.

HARLEY, J. Brian. Maps, Knowledge and Power. In: COSGROVE, Denis; DANIELS, Stephen (ed.). The Iconography of Landscape: Essays on the Symbolic Representations, Design, and Use of the Pass Environments. New York: Cambridge University Press, 1988.

JACKSON, Ashley. Cap. The Map in Red. In: JACKSON, Ashley. British Empire: A Very Short Introduction. Oxford: Oxford University Press, 2013.

LUCENA GIRALDO, Manuel. Laboratorio tropical: la expedición de límites al Orinoco, 1750-1767. Caracas: Monte Avila, 1993.

MENCK, José Theodoro. A Questão do Rio Pirara (1829-1904). Brasília: Fundação Alexandre de Gusmão, 2009.

MINGUET, Hélène. Introdução. In: LA CONDAMINE, Charles-Marie de. Viagem pelo Amazonas 1735-1745. São Paulo: Edusp; Rio de Janeiro: Nova Fronteira, 1992. MIRAS, Julia Trujillo; GONGORA, Majol Fávero (org.). Makunaima grita! Terra Indígena Raposa Serra do Sol e os direitos constitucionais no Brasil. Rio de Janeiro: Beco do Azougue, 2009.

MORAES, Antonio Carlos R. Território e História no Brasil. São Paulo: Hucitec, 2002. NABUCO, Joaquim. Question des limites du Brésil et de la Guyane Anglaise soumise à l'arbitrage de S. M. le Roi d'Italie. Atlas accompagnant le lère Mémoire du Brésil. Paris: Ducoutioux et Huillard, 1903.

OLIVEIRA, Reginaldo. A herança dos descaminhos na formação do Estado de Roraima. 2003. Tese (Doutorado em História) - FFLCH, Universidade de São Paulo (USP). São Paulo, 2003.

PASSETTI, Gabriel. Os britânicos e seu império: debates e novos campos da historiografia do período vitoriano. História (São Paulo), v. 35, n. 77, p. 1-24, 2016.

PRATT, Mary Louise. Os Olhos do Império: relatos de viagem e transculturação. Bauru: Edusc, 1999.

RAMINELLI, Ronald. Ciência e colonização - viagem filosófica de Alexandre Rodrigues Ferreira. Tempo, Niterói: UFF, n. 6, p. 157-182, 1998. 
REIS, Arthur César F. Lobo d'Almada: um estadista colonial. São Paulo: Martins Fontes, 2006.

RIO BRANCO, Barão do. Obras do Barão do Rio Branco. II: Questões de Limites com a Guiana Inglesa. Brasília: Fundação Alexandre de Gusmão, 2012.

RIVIĖRE, Peter. Absent-Minded Imperialism: Britain and Expansion of Empire in Nineteenth-Century Brazil. London: Tauris Academic Studies, 1995.

RIVIĖRE, Peter. The Forgotten Frontier. Ranchers of Northern Brazil. New York: Holt, Rinehart \& Winston, 1972.

RIVIĖRE, Peter. Introduction. In: RIVIÈRE, Peter (ed.). The Guiana Travels of Robert Schomburgk 1835-1844: Explorations on Behalf of Royal Geographical Society 1835-1839. v. 1. Aldershot (Hampshire, GB): Ashgate for the Hakluyt Society, 2006. SAID, Edward. Cultura e imperialismo. São Paulo: Companhia das Letras, 2011.

SAMPAIO, Francisco Xavier R. de. Diario da Viagem que em visita da, e correição das povoações da capitania de S. Joze do Rio Negro fez o ouvidor, e intendente geral da mesma no anno de 1774 e 1775. Lisboa: Typographia da Academia, 1825.

SANTILLI, Paulo. Pemongon Patá: território Makuxi, rotas do conflito. São Paulo: Ed. Unesp, 2000.

SCHOMBURGK, Robert H. A Description of British Guiana: Geographical and Statistical. London: Simpkin, Marshall, 1840.

SCHOMBURGK, Robert H. Twelve Views in the Interior of Guiana. London: Ackermann, 1841.

SCHOMBURGK, Robert H. Visit to the Sources of the Takutu, in British Guiana. Journal of Royal Geographical Society, London, v. 13, p. 18-74, 1843.

SOUZA JR., José Alves. Tramas do cotidiano: religião, política, guerra e negócios no Grão-Pará do Setecentos. Belém: Ed. UFPA, 2010.

ST JOHN-MCALISTER, Michael. Edward Angelo Goodall (1819-1908): An Artist's Travels in British Guiana and the Crimea. Electronic British Library Journal, art. 5, 2010.

VIEIRA, Jaci Guilherme; GOMES FILHO, Gregório F. Forte São Joaquim: do marco da ocupação portuguesa do Vale do Rio Branco às batalhas da memória - século XVIII ao XX. Textos \& Debates, Boa Vista, n. 20, p. 101-119, 2013.

WATERTON, Charles. Wanderings in South America. London: Oxford University Press, 1973.

WINICHAKUL, Thongchai. Siam Mapped: a History of the Geo-body of a Nation. Honolulu: University of Hawaii Press, 1994.

WITHEHEAD, Neil. Lords of the Tiger Spirit: A History of the Caribs in Colonial Venezuela and Guyana, 1498-1920. Dordretch (South Holland): Foris, 1988. 


\section{NOTAS}

${ }^{1}$ Este artigo é um dos resultados da pesquisa do projeto "Imperialismo em áreas de fronteira: saber e poder de mãos dadas”, desenvolvido no Programa de Pós-Graduação em História da Universidade Federal do Estado do Rio de Janeiro (UniRio), finalizado em dezembro de 2016. O projeto contou com financiamento do CNPq e do Departamento de Pesquisa da UniRio na concessão de bolsas de Iniciação Científica. Sou extremamente grato ao trabalho desenvolvido pelos bolsistas, em particular por Gabriel Vecchietti Salvaterra Dutra, na pesquisa com as fontes do Arquivo Histórico do Itamaraty.

2 Em artigo claro e objetivo, Gabriel Passetti faz uma análise dessa historiografia (PASSETTI, 2016). Destacamos Paul Carter e sua desconstrução da história da colonização da Austrália, publicada originalmente em 1987, uma história que "reduces space to a stage, that pays attention to events unfolding in time alone", cujo objeto primário "is not to understand or to interprete: it is to legitimate" (CARTER, 2010, p. xvi). Grande parte dessa crítica à história imperial, especialmente o olhar da nova história geográfica, deve-se à desconstrução do discurso científico produzida por Michel Foucault, particularmente no que se refere aos espaços heterotópicos e à Geografia (FOUCAULT, 2009, p. 411-422; FOUCAULT, 1996, p. 153-165). Indicamos a seguir, além dos trabalhos que se referem diretamente à nossa região em estudo, também alguns dos principais trabalhos produzidos nessa linha: (RIVIÈRE, 1995; BURNETT, 2000; SAID, 2011; HARLEY, 1988; PRATT, 1999; WINICHAKUL, 1994; WHITEHEAD, 1988).

${ }^{3}$ Estudar as fronteiras numa perspectiva contra-hegemônica é apresentar diferentes realidades nacionais, a multiplicidade de suas histórias, e acentuá-las como principal característica da realidade brasileira, confrontando a centralidade da história imperial.

${ }^{4}$ A lógica territorialista e a lógica capitalista foram conceitualmente apresentadas por Giovanni Arrighi ao classificar os sucessivos padrões hegemônicos do capitalismo histórico (ARRIGHI, 1966).

${ }^{5}$ Memoria ou observações sobre a questão de limites entre a Guiana Brasileira e Inglêsa do lado do Rio Branco e seus afluentes, 1841. Bernardo de Souza Franco. Série Limites: Setor Guiana Britânica 1840-1911. Lata 465, Vol./maço 02. Arquivo Histórico do Itamaraty, AHI, Rio de Janeiro.

${ }^{6} \mathrm{O}$ trabalho mais elucidativo sobre a passagem de Schomburgk pelo Pirara é o de Peter Rivière (1995). Confrontando a interpretação do antropólogo inglês, temos o extensivo trabalho de história diplomática elaborado por José Theodoro Menck (2009) que procura mostrar a usurpação da soberania brasileira na região pelo imperialismo inglês. $\mathrm{O}$ trabalho de Destro (2006) segue a mesma lógica. Em contraponto, temos a coletânea organizada por Miras e Gongora (2009).

${ }^{7}$ Do lado brasileiro, principalmente na primeira década após a neutralização, há um conjunto de remessas documentais para Londres: ver cópias de documentos referentes à questão de limites com a Guiana Britânica, a serem remetidas para a missão especial em 
Londres. Visconde do Uruguai, 1841-1853. Série Limites: Setor Guiana Britânica 18401911. Lata 465, Vol./maço 04. AHI.

${ }^{8}$ A defesa brasileira foi apresentada por Joaquim Nabuco (1903). Segue o Map of Guyana to illustrate the route of R. H. Schomburgk (desenhado por John Murray), Journal of the Royal Geographical Society, Londres, 1840.

${ }^{9} \mathrm{O}$ Barão do Rio Branco registra o fato de que o capitão Francisco Ferreira teria feito diversas expedições subindo o rio Tacutu e chegado a Pirara no ano de 1700 (RIO BRANCO, 2012, p. 40). Joaquim Nabuco, da mesma forma ao escrever sua Primeira Memória, afirma que Ferreira alcançou o rio Amucu. Ambos baseiam-se nas informações colhidas pelo ouvidor Francisco Xavier Ribeiro Sampaio em relatório datado do ano de 1777. Contudo, essa primazia não foi reconhecida pela arbitragem internacional do litígio por ausência de provas documentais.

${ }^{10} \mathrm{O}$ trecho do diário de viagem em que Horstman descreve os rios Negro, Parima, Maú, Tacutu e Rupununi, mapeando o encontro das bacias do Amazonas com o Essequibo, foi anexado na memória apresentada por Joaquim Nabuco em Milão. O croqui que mostra sua passagem por Pirara pode ser visualizado em artigo publicado por Júnia Ferreira Furtado (FURTADO, 2013, p. 716).

${ }^{11}$ Como observaram Alès \& Pouyllau (1992, p. 298) logo após a passagem de Horstman, o lago de Parima que vinha sendo representado pela cartografia da época como um grande mar interior, desaparece, dando lugar ao lago Amucu, ponto de passagem para o rio Maú e Branco. Paulatinamente até Humboldt, o lago Parima passa a ser compreendido como um ponto de passagem para a bacia hidrográfica do Orinoco. Nesse mesmo artigo podem ser vistas as diversas cartas estudadas por Humboldt, entre elas a de Horstman, antes de sua viagem à Venezuela. [Fig. 13. Onze cartes étudiées par Humboldt (1800)].

${ }^{12}$ A expedição de Miguel Ayres encerra o ciclo de entradas com o aporte oficial da Coroa portuguesa. Em 1755, Portugal proibiu formalmente o apresamento de indígenas. Extraoficialmente, as incursões de tropas de resgate de portugueses e brasileiros continuarão até quase meados do século XIX. Em grande parte, saindo das próprias fortificações militares, o que indica uma clara inobservância da proibição.

${ }^{13}$ Schomburgk não menciona nenhuma ocupação holandesa ou inglesa no curso alto do Essequibo, somente aldeias Wapixana. Bartica, a última povoação no Essequibo, encontrava-se próxima à costa.

${ }^{14}$ A expedição aparece indicada no compêndio de Isa Adonias (1963, p. 149). Não foi possível precisar se chegaram ao rio Maú somente até encontrar o Tacutu ou se o alferes logrou subir suas corredeiras.

${ }^{15}$ De acordo com Peter Rivière o povoamento com rancheiros no rio Branco não ocorrerá antes do ano de 1787 (RIVIĖRE, 1972).

${ }^{16}$ A carta desenhada no âmbito dessa expedição foi reproduzida no atlas que acompanha a primeira memória de Joaquim Nabuco (1903, p. 44-45).

${ }^{17}$ Graham Burnett (2000, p. 244-245) mostra a contradição do discurso humanitário britâ- 
nico na minuta adicionada ao relatório de Schomburgk em setembro de 1841 por James Stephen, então subsecretário de Estado para as colônias, na qual se referia a indivíduos britânicos na Austrália que "perpetrated enormities against Native Tribes compared with which even the alleged crimes of the Spaniards in Guiana are insignificant". PRO, Public Record Office (atual National Archives), Kew, CO, 111/179.

18 "Memorandum on Boundaries of Guiana and procedures", com duas notas do Ministro Ouseley, 1841. Série Limites: Setor Guiana Britânica 1840-1911. Lata 465, Vol./maço 03. AHI.

${ }^{19} \mathrm{O}$ mapa de Frederico Carneiro de Campos está disponível em forma digital no acervo da Biblioteca Nacional: http://objdigital.bn.br/objdigital2/acervo_digital/div_cartografia/ cart525804/cart525804.html.

${ }^{20}$ Comissão exploradora dos territórios contestados ao Império pela Guiana Inglesa..., 1843-1844; Relatório dos trabalhos executados pela comissão exploradora e parecer sobre os limites do Império com as Guianas, 1844. Série Limites: Setor Guiana Britânica 18401911. Vol./maço 05. AHI.

${ }^{21}$ Parecer sobre os trabalhos da comissão. Relatores: Francisco Cordeiro da Silva e Pedro Alcântara Bellegarde, 1844. Série Limites: Setor Guiana Britânica 1840-1911. Vol./maço 05. AHI. 